\title{
MARCHA DE ABSORÇÃO DE NITROGENIO, FÓSFORO, POTÁSSIO, CÁLCIO E MAGNÉSIO NA CULTURA \\ DA MAMONEIRA (Ricinus communis, L.), CULTIVAR "CAMPINAS" *
}

\author{
JÚlio NAKAgAWA **
}

A. M. Louis Neptune ***

\begin{abstract}
O presente trabalho foi realizado com a finalidade de se estudar a marcha de absorção de nitrogênio, fósforo, potássio, cálcio e magnésio e do desenvolvimento da mamoneira, em condições de campo, na presença e ausência de calcário dolomítico e de adubação N P K.

$O$ período de maior absorção não ficou bem caracterizado para todo o ensaio, enrtetanto, para os tratamentos adubados os elementos nitrogênio, fósforo, potássio e magnésio foram absorvidos com maior intensidade entre 41 e 110 dias, e o cálcio entre 41 e 87 dias. Não se observou efeito significativo do calcário no pêso de plantas sêcas mas o adubo influiu no desenvolvimento, na absorção dos elementos $(\mathrm{N}, \mathrm{P}, \mathrm{K}, \mathrm{Ca} e$ $\mathrm{Mg}$ ) e na produção de frutos.
\end{abstract}

\section{INTRODUÇÃO}

As primeiras neferências sôbre a composição química da mamoneira, no Brasil, foram apresentadas por GRANATO (1918), citando que em média as porcentagens de nitrogênio, potasa e ácido fosfórico eram respectivamente $1,39 \%, 1,25 \%$ e $0,36 \%$. TUCKER (1952) determinou as concentrações de nitrogênio, fósforo e potássio, na parte aérea de plantas cultivadas em solução nutritiva, e encontrou $2,41 \%$, $0,20 \%$ e $0,14 \%$, respectivamente para aquêles três elementos. ITURRIETA ROJAS (1970) analisou as diferentes partes da mamoneira, cultivada em solução nutritiva, e os resultados mostraram grandes variações na concentração de um mesmo nutriente, em função das partes e da idade dessas partes da planta.

GRANATO (1918), baseado nos resultados obtidos por D'Utra, calculou que a mamoneira retirou $5,2 \mathrm{~kg}$ de $\mathrm{N}, 3,8 \mathrm{~kg}$ de $\mathrm{P}_{2} \mathrm{O}_{\tilde{5}}, 2,9 \mathrm{~kg}$ de $\mathrm{K}_{2} \mathrm{O}$ e $1,1 \mathrm{~kg}$ de $\mathrm{CaO}$, por $100 \mathrm{~kg}$ de sementes. CANECCHIO FILHO \& FREIRE (1958) estimaram que $2.000 \mathrm{~kg}$ de sementes com as cascas correspondentes retiram do solo, aproximadamente, $80 \mathrm{~kg}$ de $\mathrm{N}, 18 \mathrm{~kg}$ de $\mathrm{P}_{2} \mathrm{O}_{5}, 32 \mathrm{~kg}$ de $\mathrm{K}_{2} \mathrm{O}$ e $10 \mathrm{~kg}$ de $\mathrm{MgO}$.

\footnotetext{
* Trabalho realizado com parte dos dados da Tese de Doutoramento apresentada à Faculdade de Ciências Médicas e Biológicas de Botucatu, pelo Eng.o Agr.o Júlio NAKAGAWA.

** Departamento de Agrotecnia e Geologia - F.C.M.B.B. - Botucatu.

**: Departamento de Solos e Geologia - E.S.A.L.Q. - U.S.P.
} 
Como se observa pela literatura, que ainda não se conhece como se desenvolve a absorção dos elementos minerais pela mamoneira. Diante dessa problemática, realizou-se o presente trabalho em que se procurou estudar a marcha de absorção de nitrogênio, fósforo, potássio, cálcio e magnésio, e o desenvolvimento da cultura, em condições de campo, na presença e ausência de calcário dolomítico e da adubação NPK.

\section{MATERIAIS E MÉTODOS}

Utilizou-se um delineamento experimental de blocos ao acaso, com seis repetições, envolvendo quatro tratamentos: $\mathrm{T}$ - sem calcário e sem adubo; C - com calcário dolomítico na base de $800 \mathrm{~kg} / \mathrm{ha}$; A - sem calcário e com 80, 100 e $40 \mathrm{~kg} / \mathrm{ha}$ de $\mathrm{N}, \mathrm{P}_{2} \mathrm{O}_{5}$ e $\mathrm{K}_{2} \mathrm{O}$, respectivamente; $(\mathrm{A}+\mathrm{C})$ - incluindo as doses de calcário e de adubo, utilizadas nos tratamentos $\mathrm{A}$ e $\mathrm{C}$.

Segundo a COMISSÃO DE SOLOS (1960), o solo, onde se localizou o ensaio, pertence ao grande grupo Latosol Vermelho Amarelo, fase-arenosa. Na amostra composta, retirada dêsse solo, fêz-se as seguintes determinações: a) o valor $\mathrm{pH}$, utilizando-se relação $1: 2,5$ para solo: água; b) matéria orgânica, pelo método descrito em MALAVOLTA \& COURY (1954); c) hidrogênio e potássio trocáveis e o fósforo solúvel, conforme os métodos descritos em CATANI et al. (1955); d) cálcio e magnésio trocáveis, utilizando-se o método de EDTA, de GLÓRIA et al. (1965). Os resultados seguem em QUADRO I, onde se observa tratar-se de um solo levemente ácido e pobre na maioria dos nutrientes analisados, pela interpretação dada em CATANI et al. (1955).

Como corretivo utilizou-se um calcário dolomítico procedente de Pereiras, Estado de São Paulo, e os fertilizantes que serviram de fontes de N, P e K foram sulfato de amônio, superfosfato triplo e cloreto de potássio, respectivamente. A calagem foi efetuada a 01/10/1969 e a adubação, por ocasião do plantio. Apenas o nitrogênio foi dividido em duas aplicações, tendo-se colocado um terço no plantio e os dois terços restantes, aplicados em cobertura, 50 dias após o plantio.

O espaçamento adotado foi $1,50 \mathrm{~m}$ nas entre linhas e $0,50 \mathrm{~m}$ entre covas, baseado nosi trabalhos de ROCHA et al. (1964). Em função dêste espaçamento determinou-se uma área da parcela, que comportasse 4 linhas de 8 plantas. Portanto a área da prcela foi de $24,00 \mathrm{~m}^{2}$ $(6,0 \times 4,0 \mathrm{~m})$.

Efetuou-se a semeadura aos 24/10/1969, colocando-se três sementes por cova, de acôrdo com ROCHA et al. (1964), e utilizando-se o cultivar "Campinas", de frutos indeiscentes e porte médio, conforme descrição de BANZATO \& ROCHA (1965).

$\mathrm{O}$ excesso de plantas germinadas foi sendo eliminado e aos vinte dias após o plantio, todas as parcelas contavam com apenas uma 
planta por cova. Durante a condução do ensaio, três capinas foram suficientes para manter as parcelas livres de ervas daninhas e nenhuma outra operação foi necessário.

Com intervalos regulares de 23 dias entre amostragens, foram coletadas uma planta por parcela, num total de cinco amostragens. A primeira foi efetuada aos 41 dias e a última aos 133 dias após o plantio. As plantas foram cortadas rente ao solo, lavadas, e em seguida colocadas em estufa ajustada para temperatura entre 65 e $70^{\circ} \mathrm{C}$. Após sêcas foram pesadas e moídas em moinho tipo "Wiley". O material moído foi submetido a análises químicas.

$\mathrm{Na}$ determinação do nitrogênio utilizou-se o método do micro Kjeldahl, descrito em MALAVOLTA (1965). Para determinação de fósforo, potássio, cálcio e magnésio, fêz-se a digestão nítrico-perclórico do material vegetal, obtendo-se o extrato. Nesse extrato, determinaram-se o fósforo pelo método fotocolorimétrico, descrito por LOTT et al. (1965), o potássio por fotometria de chama e o cálcio e o magnésio, pelo método do EDTA de GLORIA et al. (1965).

Apenas duas colheitas foram suficientes e estas se realizaram aos 15/06/1970 e 25/07/1970. Os frutos foram separados em cascas e sementes. Estas duas partes foram também submetidas a análises químicas, utilizando-se os métodos de análises para plantas, já descritos anteriormente.

QUADRO 1 - Características químicas do solo utilizado do ensaio.

\begin{tabular}{l|c|c|c|c|c|c}
\hline & \multirow{6}{*}{$\begin{array}{c}\text { M.O. } \\
\text { pH }\end{array}$} & $\mathrm{H}$ & $\mathrm{PO}_{4}^{3-}$ & $\mathrm{K}$ & $\mathrm{Ca}^{2+}$ & $\mathrm{Mg}^{2+}$ \\
\cline { 3 - 7 } & 0,73 & 2,60 & 0,03 & 0,08 & 2,26 & 0,80 \\
\hline
\end{tabular}

\section{RESULTADOS E DISCUSSÃO}

A Figura 1 e o Quadro 2 mostram o efeito do adubo no desenvolvimento das plantas mas não do calcário.

$\mathrm{O}$ efeito do abubo se deve provàvelmente à pobreza do solo ütilizado no ensaio, em nitrogênio, fósforo e potássio que foram os três elementos químicos fornecidos como adubo.

A pequena resposta das plantas ao calcário, no aumento de peso de matéria seca, pode ser atribuída à presença de cálcio e de magnésio em quantidades suficientes no solo e, por outro lado, à leve acidez deste solo, que não chiegaram a prejudicar o bom desenvolvimento da cultura. 
A época de emissão de inflorescências das plantas dos tratamentos A e $(\mathrm{A}+\mathrm{C})$ coincidiu, dentro de certos limites, com aquela citada para o cultivar por BANZATO \& ROCHA (1965). Nos tratamentos $\mathrm{T}$ e $\mathrm{C}$, ocorreu um certo retardamento na emissão dessas inflorescências, em consequência do atraso no desenvolvimento das plantas.

\section{Concentração dos elementos $\mathrm{N}, \mathrm{P}, \mathrm{K}, \mathrm{Ca}$ e $\mathrm{Mg}$ nas plantas.}

O Quadro 3 fornece as médias de concentração dos nutrientes analisados quimicamente.

Em linhas gerais os tratamentos adubados apresentaram concentrações maiores de nutrientes porém o fenomeno foi mais acentuado no caso do fósforo. Via de regra as concentrações dos elementos na planta, aos 64 dias, foram maiores do que nas demais amostragens. A partir dessa data de amostragem começaram a diluir-se. O potássio foi uma exceção, pois as maiores concentrações foram verificadas na primeira amostragem.

Algumas culturas com ciclo vegetativo definido, como alface, arroz, couve-flôr e cebola, começaram a apresentar uma diminuição nas concentrações de $\mathrm{N}, \mathrm{P}, \mathrm{K}, \mathrm{Ca}$ e Mg, em torno de 50 a 60 dias de vida das plantas, conforme pode-se observar nos trabalhos de ZINK \& YAMAGUCHI (1962), de GARGANTINI \& GARCIA BLANCO (1965), de ZINK (1966) e de HOMA et al. (1969). Outras culturas, cujo ciclo vegetativo não é bem determinado, como tomateiro e beringela, também não apresentam uma época definida em que os teores dos nutrientes minerais, antes referidos, começam a se diluírem dentro das plantas, GARGANTINI \& GARCIA BLANCO (1963) e HAAG \& HOMA (1968). Portanto, o início da diluição dos nutrientes na planta parece estar relacionado com o ciclo vegetativo das culturas. Evidentemente, no presente trabalho, em que a cultura foi reconhecida como tendo um ciclo vegetativo definido, por BANZATO \& ROCHA (1965), a diminuição na concentração dos elementos $\mathrm{N}$, $\mathrm{P}, \mathrm{K}, \mathrm{Ca}$ e $\mathrm{Mg}$ na mamoneira, também, teve um período definido, observando-se, portanto, coerência com os fatos verificados por outros autores em outras culturas.

\section{Marcha de absorção e quantidades de elementos absorvidos}

Pelas figuras 2, 3, 4, 5 e 6, verifica-se que as curvas de absorção dos elementos estudados dos tratamentos $\mathrm{T}$ e $\mathrm{C}$, acompanharam as curvas de crescimento das plantas. Figura 1. Em relação aos tratamentos adubados, observa-se que as curvas de absorção de nitrogênio, fósforo e potássio se assemelham mais às curvas de crescimento dos tratamentos correspondentes, do que às de cálcio e de magnésio nesses tratamentos adubados. 
Os dados do quadro 4, 5, 6, 7 e 8 mostram que apenas o adubo influenciou grandemente a absorção dos elementos estudados.

ITURRIETA ROJAS (1970) mostra em seu trabalho que o fósforo foi o único nutriente que influiu significativamente no desenvolvimento do sistema radicular do cultivar 'Campinas'. No presente trabalho foi observado que as plantas dos tratamentos $\mathrm{T}$ e $\mathrm{C}$, apresentaram absorção paulatina e quantitativamente menor de fósforo. Como o solo, do local do ensaio era paupérrimo em fósforo, o sistema radicular das plantas daqueles tratamentos não deve ter desenvolvido suficientemente, prejudicando consequentemente a absorção qualitativa e quantitativa dos nutrientes. Contràriamente, os tratamentos adubados, recebendo fósforo, permitiram que as plantas neles desenvolvidas encontrassem condições favoráveis para um bom desenvolvimento do seu sistema radicular e, absorvessem maior quantidade de $\mathrm{N}, \mathrm{P}, \mathrm{K}, \mathrm{Ca}$ e $\mathrm{Mg}$.

$O$ fato de as plantas dos tratamentos $\mathrm{C}$ e $(\mathrm{A}+\mathrm{C})$ terem absorvido de um modo geral, um pouco mais nutrientes do que aquelas dos tratamentos $\mathrm{T}$ e $\mathrm{A}$, provàvelmente, se relaciona com a ação do calcário na liberação de alguns elementos tornando-os disponíveis às plantas, NEPTUNE (1964).

As quantidades de $\mathrm{N}, \mathrm{P}, \mathrm{K}, \mathrm{Ca}$ e $\mathrm{Mg}$ retiradas do solo, pelas plantas do presente ensaio, superaram largamente aquelas observadas por ITURRIETA ROJAS (1970), apesar de se tratar de mesmo cultivar. Tudo indica que as diferentes condições, em que se efetuaram os dois estudos tenham sido a causa principal do acontecimento. Em condições de campo, o sistema radicular das plantas não tem a limitação a que está sujeito quando em vaso, encontrado, portanto, situações melhores para se desenvolver e fazer refletir êsse seu desenvolvimento à parte aérea. Aliás, os pesos de plantas do tratamento $\mathrm{T}$ eram próximos daqueles do tratamento Completo da autora, mostrando assim, a grande influência do meio.

Com relação às exportações dos elementos minerais pelos frutos, CANECCHIO FILHO \& FREIRE (1958) avaliaram que $2.000 \mathrm{~kg}$ de sementes e suas cascas retiram aproximadamente $80 \mathrm{~kg}$ de $\mathrm{N}, 18 \mathrm{~kg}$ de $\mathrm{P}_{2} \mathrm{O}_{5}, 32 \mathrm{~kg}$ de $\mathrm{K}_{2} \mathrm{O}, 13 \mathrm{~kg}$ de $\mathrm{CaO}$ e $10 \mathrm{~kg}$ de $\mathrm{MgO}$. No presente trabalho, para essa mesma produção de $2.000 \mathrm{~kg}$ de sementes com as cascas, o cultivar 'Campinas' retirou $73,84 \mathrm{~kg}$ de $\mathrm{N}, 15,42 \mathrm{~kg}$ de $\mathrm{P}_{2} \mathrm{O}_{5}, 24,32 \mathrm{~kg}$ de $\mathrm{K}_{2} \mathrm{O}, 14,24 \mathrm{~kg}$ de $\mathrm{CaO}$ e $17,30 \mathrm{~kg}$ de $\mathrm{MgO}$. Várias causas devem estar envolvidas na discrepância dêsses dois dados aqui relatados. Fundamentalmente, porém, tal discordância se prende ao fato de que aquêles autores tomaram médias de análises químicas de três amostras de fontes diferentes, cujas variedades eram desconhecidas. BRIGHAM et al. (1963), estudando os efeitos de nitrogênio, fósforo e potássio em três variedades de mamona, em mesmas con- 
dições de clima e solo, observaram que duas das variedades produziram mais com doses $80-40-40\left(\mathrm{~N}-\mathrm{P}_{2} \mathrm{O}_{5}-\mathrm{K}_{2} \mathrm{O}\right)$ enquanto a terceira reagiu melhor à aplicação de $120-40-0\left(\mathrm{~N}-\mathrm{P}_{2} \mathrm{O}_{5}-\mathrm{K}_{2} 0\right)$, em libras/acre. Isto evidencia que diferentes variedades da cultura apresentam diferentes exigencias minerais e explica os diferentes resultados obtidos nos dois trabalhos, em discussão neste parágrafo.

\section{Produção de sementes}

O Quadro 9 fornece os pesos médios de frutos e de suas partes, sementes e cascas, bem como, as porcentagens dessas partes no fruto e as relações \% de sementes/\% de cascas.

A análise da variência mostrou que os frutos e suas partes aumentaram significativamente nas parcelas com adubação.

MARCOS FILHO \& GODOY (1971) citam que a produção média por hectare, dêste cultivar gira em tôrno de $3.000 \mathrm{~kg}$ de sementes.

As plantas dos tratamentos adubados proporcionaram em média uma produção de frutos superior a $3.000 \mathrm{~kg} / \mathrm{ha}$ enquanto as dos tratamentos sem adubo não atingiram $2.000 \mathrm{~kg} / \mathrm{ha}$. Essa produção maior das parcelas adubadas foi motivada não só pela emissão de um maior número de cachos mas devido, também, à maior relação entre $\%$ de sementes e $\%$ de cascas, proporcionada pelos frutos das parcelas adubadas. Isto significa que, no fruto das plantas adubadas, as sementes tiveram seu pêso aumentado enquanto as cascas preservaram pràticamente a mesma massa. A propósito, o pêso de 100 sementes, provenientes de plantas adubadas, foi em tôrno de 42 gramas enquanto as plantas do tratamento $\mathrm{T}$ produziram sementes pesando cêrca de 38 gramas por 100 sementes. Portanto, o que se verificou de fato é que o adubo além de aumentar o número de frutos, tornou as bagas mais pesadas.

\section{CONCLUSÕES}

Os resultados obtidos no presente trabalho permitiram tirar as seguintes conclusões referentes à parte aérea da mamoneira :

a) As maiores concentrações de N, P, K nas plantas foram determinados no primeiro mês do ciclo vegetativo, e as de cálcio e magnésio, no segundo mês.

b) O período de maior absorção não ficou bem caracterizado para o ensaio todo, entretanto, para os tratamentos com adubo os elementos $\mathrm{N}, \mathrm{P}, \mathrm{K}$ e $\mathrm{Mg}$ tiveram o período de 41 a 110 dias, como o de maior intensidade, e o de cálcio situou entre 41 e 87 dias.

c) Não se constatou efeito do calcário no pêso de plantas e na produção de frutos.

d) O adubo aumentou a absorção dos elementos (N, P, K, Ca e $\mathrm{Mg}$ ), o pêso de plantas e a produção de frutos. 


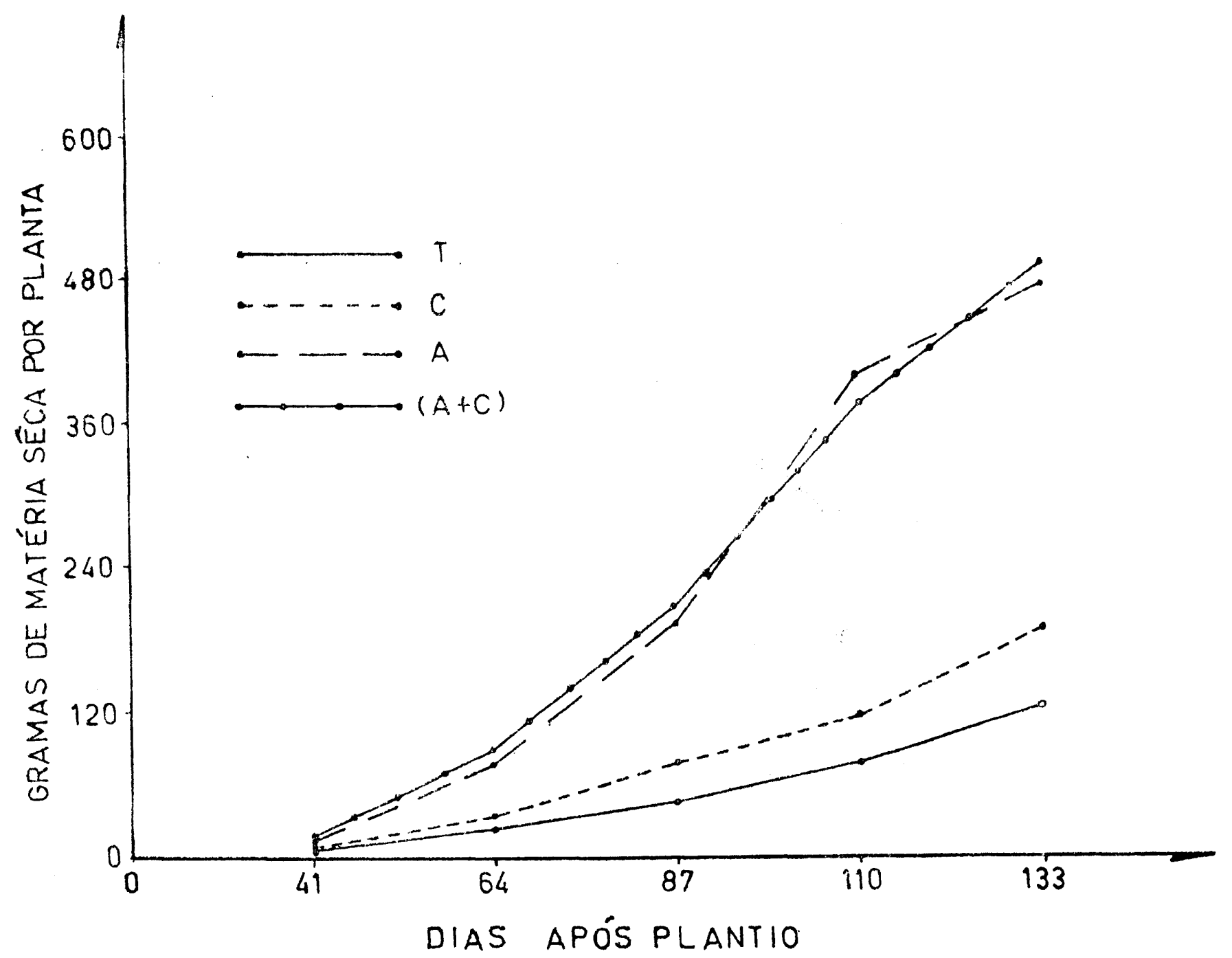

FIGURA 1 - Curvas de crescimento das plantas do cultivar "Campinas", em diferentes estágios. Média de seis repetições.

QUADRO 2 - Peso em gramas de planta inteira seca, em diferentes estágios de desenvolvimento do cultivar "Campinas". Média de seis repetições.

\begin{tabular}{c|rrrrc}
\hline \multirow{2}{*}{$\begin{array}{c}\text { Trata- } \\
\text { mentos }\end{array}$} & \multicolumn{5}{c}{ Dias após o plantio } \\
\cline { 2 - 6 } & 41 & 64 & 87 & 110 & 133 \\
\hline T & 2,01 & 25,11 & 44,73 & 78,69 & 127,19 \\
C & 2,56 & 32,78 & 64,66 & 119,38 & 190,80 \\
A & 9,93 & 76,49 & 197,78 & 413,06 & 466,86 \\
(A+C) & 10,19 & 105,60 & 216,43 & 389,33 & 493,16 \\
\hline d.ms. 5\% & 2,45 & 31,16 & 87,85 & 197,66 & 149,40 \\
\hline C.V. \% & 23,80 & 31,18 & 40,29 & 47,45 & 28,07 \\
\hline
\end{tabular}


QUADRO 3 - Porcentagens de nitrogênio, fósforo, potássio, cálcio e magnésio, na parte aérea do cultivar "Campinas", em diferentes estágios de desenvolvimento. Média de seis repetições.

\begin{tabular}{|c|c|c|c|c|c|c|}
\hline \multirow{2}{*}{$\begin{array}{c}\text { Amos. } \\
\text { tra- } \\
\text { gens }\end{array}$} & \multirow{2}{*}{$\begin{array}{l}\text { Trata- } \\
\text { mentos }\end{array}$} & \multicolumn{5}{|c|}{ Elementos nutrientes } \\
\hline & & N\% & $\mathrm{P} \%$ & $\mathrm{~K} \%$ & $\mathrm{Ca} \%$ & $\mathrm{Mg} \%$ \\
\hline & $\mathrm{T}$ & 3,89 & 0,093 & 4,57 & 0,28 & 0,28 \\
\hline 41 & C & 4,17 & 0,096 & 4,90 & 0,30 & 0,27 \\
\hline \multirow[t]{3}{*}{ dias } & A & 4,15 & 0,136 & 5,18 & 0,33 & 0,30 \\
\hline & $(A+C)$ & 4,01 & 0,141 & 5,37 & 0,32 & 0,28 \\
\hline & $\mathrm{T}$ & 4,13 & 0,085 & 4,32 & 0,36 & 0,34 \\
\hline 64 & $\mathrm{C}$ & 4,01 & 0,089 & 4,68 & 0,36 & 0,33 \\
\hline \multirow[t]{3}{*}{ dias } & A & 3,80 & 0,095 & 4,06 & 0,48 & 0,41 \\
\hline & $(A+C)$ & 3,17 & 0,102 & 4,61 & 0,46 & 0,50 \\
\hline & $\mathrm{T}$ & 2,84 & 0,066 & 3,70 & 0,36 & 0,34 \\
\hline 87 & C & 2,77 & 0,068 & 3,72 & 0,36 & 0,35 \\
\hline \multirow[t]{3}{*}{ dias } & A & 2,82 & 0,076 & 3,44 & 0,36 & 0,35 \\
\hline & $(A+C)$ & 3,08 & 0,076 & 3,17 & 0,36 & 0,31 \\
\hline & $\mathrm{T}$ & 2,77 & 0,071 & 3,00 & 0,21 & 0,25 \\
\hline 110 & C & 2,61 & 0,070 & 2,59 & 0,22 & 0,28 \\
\hline \multirow[t]{3}{*}{ dias } & A & 2,73 & 0,078 & 2,74 & 0,23 & 0,27 \\
\hline & $(A+C)$ & 2,70 & 0,081 & 2,54 & 0,23 & 0,26 \\
\hline & $\mathrm{T}$ & 2,38 & 0,071 & 2,51 & 0,22 & 0,22 \\
\hline 133 & C & 2,42 & 0,074 & 2,45 & 0,23 & 0,19 \\
\hline \multirow[t]{2}{*}{ dias } & A & 2,28 & 0,080 & 2,64 & 0,21 & 0,19 \\
\hline & $(A+C)$ & 2,38 & 0,081 & 2,61 & 0,21 & 0,19 \\
\hline
\end{tabular}




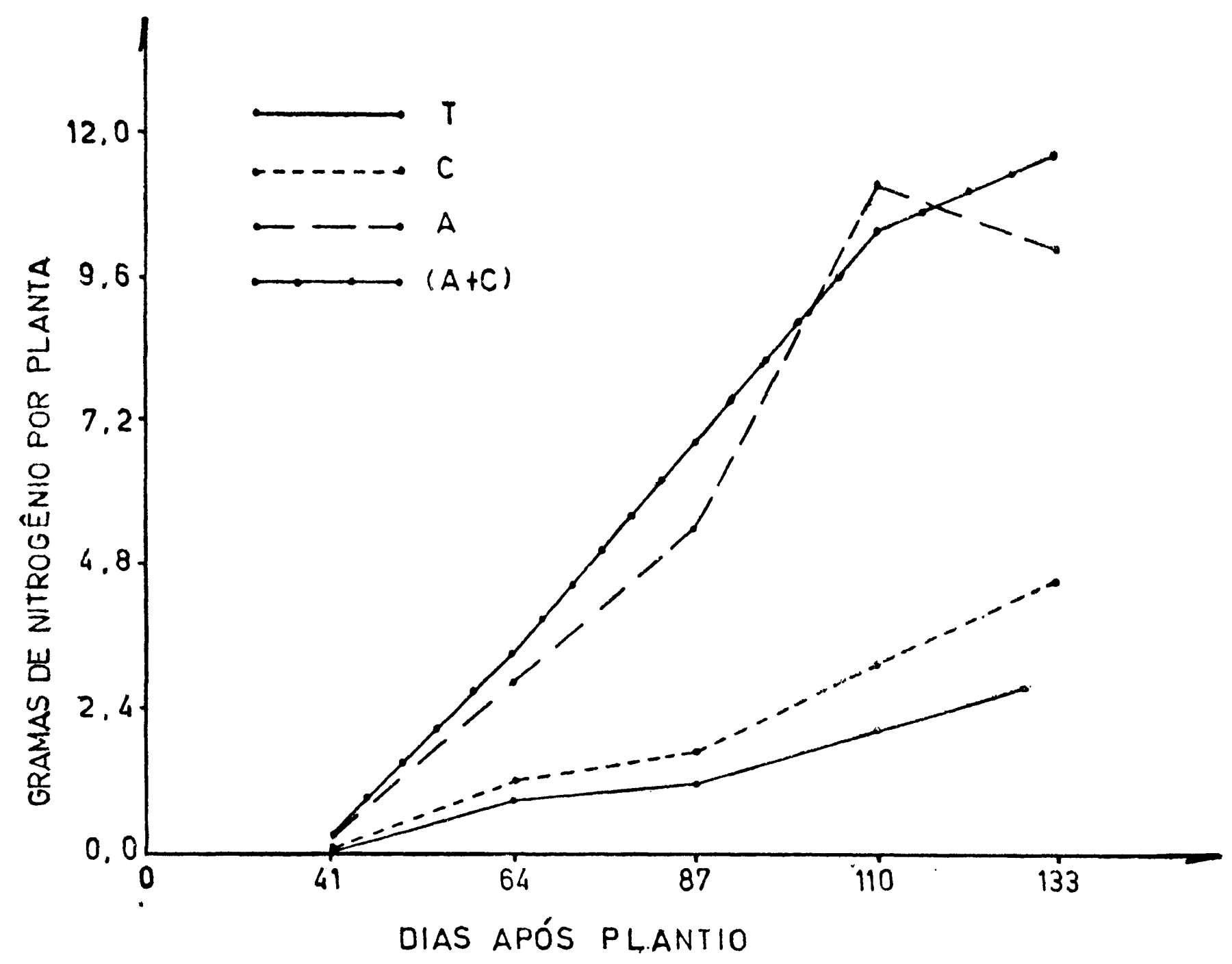

FIGURA 2 - Curvas mostrando marcha de absorção do nitrogênio pelas plantas do cultivar "Campinas". Média de seis repetições.

QUADRO 4 - Extração média de nitrogênio, em $\mathrm{kg} / \mathrm{ha}$, em vários estágios de desenvolvimento, pelo cultivar "Campinas).

\begin{tabular}{crrrrr}
\hline \multirow{2}{*}{$\begin{array}{c}\text { Trata- } \\
\text { mentos }\end{array}$} & \multicolumn{5}{c}{ Dias após o plantio } \\
\cline { 2 - 5 } & 41 & 64 & 87 & 110 & \multicolumn{1}{c}{133} \\
\hline $\mathrm{T}$ & 1,04 & 13,82 & 16,93 & 29,06 & 40,36 \\
$\mathrm{C}$ & 1,42 & 17,53 & 23,88 & 41,54 & 61,58 \\
$\mathrm{~A}$ & 5,49 & 38,75 & 74,36 & 150,35 & 141,91 \\
$(\mathrm{~A}+\mathrm{C})$ & 5,45 & 44,63 & 88,88 & 140,16 & 156,49 \\
\hline
\end{tabular}




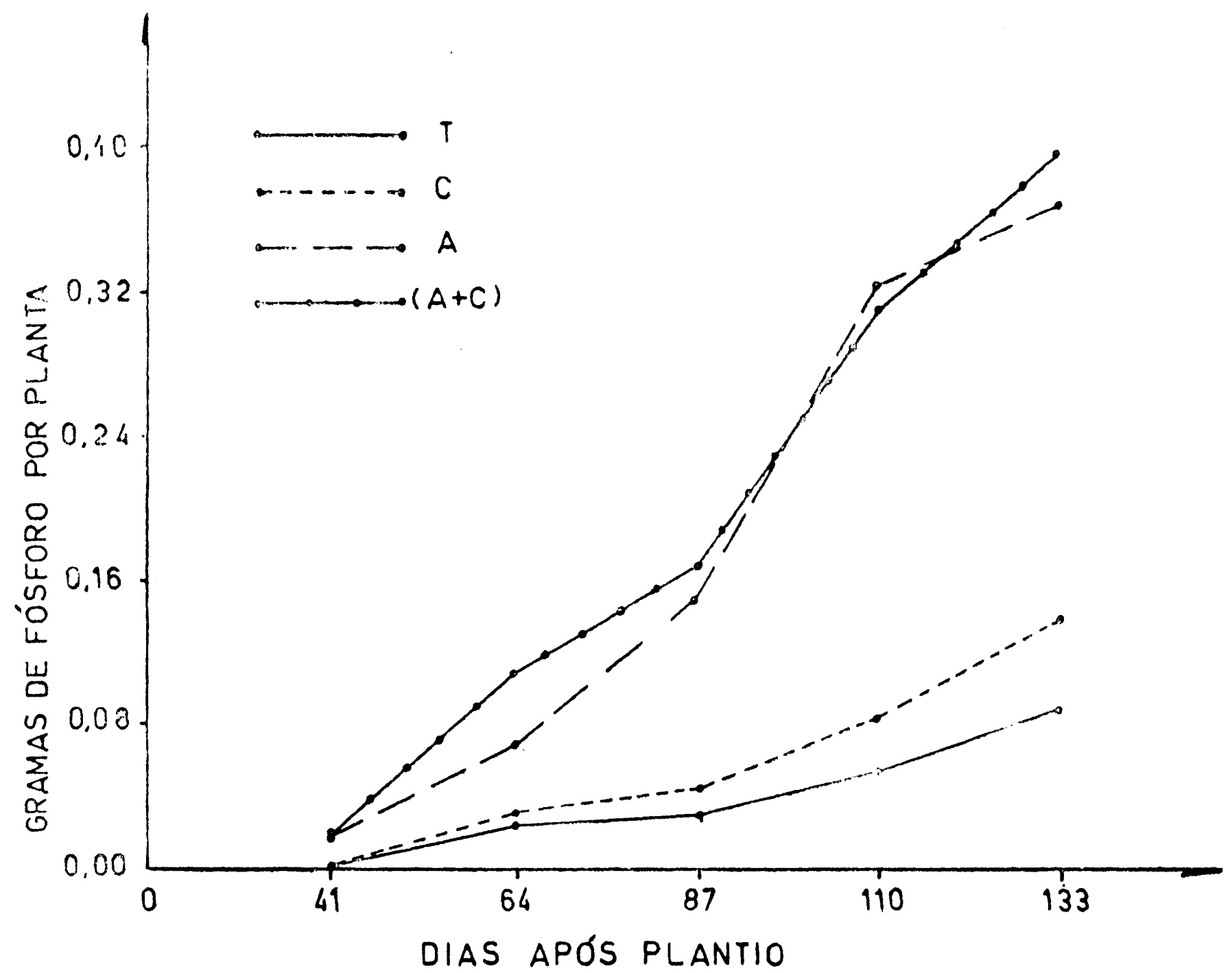

FIGURA 3 - Curvas mostrando marcha de absorção de fósforo pelas plantas do cultivar "Campinas". Média de seis repetições.

QUADRO 5 - Extração média de fósforo, em $\mathrm{kg} / \mathrm{ha}$, em vários estágios de desenvolvimento, pelo cultivar "Campinas".

\begin{tabular}{cccccc}
\hline \multirow{2}{*}{$\begin{array}{c}\text { Trata- } \\
\text { mentos }\end{array}$} & \multicolumn{5}{c}{ Dias após o plantio } \\
\cline { 2 - 5 } & 41 & 64 & 87 & 110 & 133 \\
\hline $\mathrm{T}$ & 0,02 & 0,28 & 0,39 & 0,74 & 1,20 \\
$\mathrm{C}$ & 0,03 & 0,39 & 0,59 & 1,11 & 1,88 \\
$\mathrm{~A}$ & 0,18 & 0,97 & 2,00 & 4,30 & 4,98 \\
$(\mathrm{~A}+\mathrm{C})$ & 0,19 & 1,44 & 2,19 & 4,20 & 5,33 \\
\hline
\end{tabular}




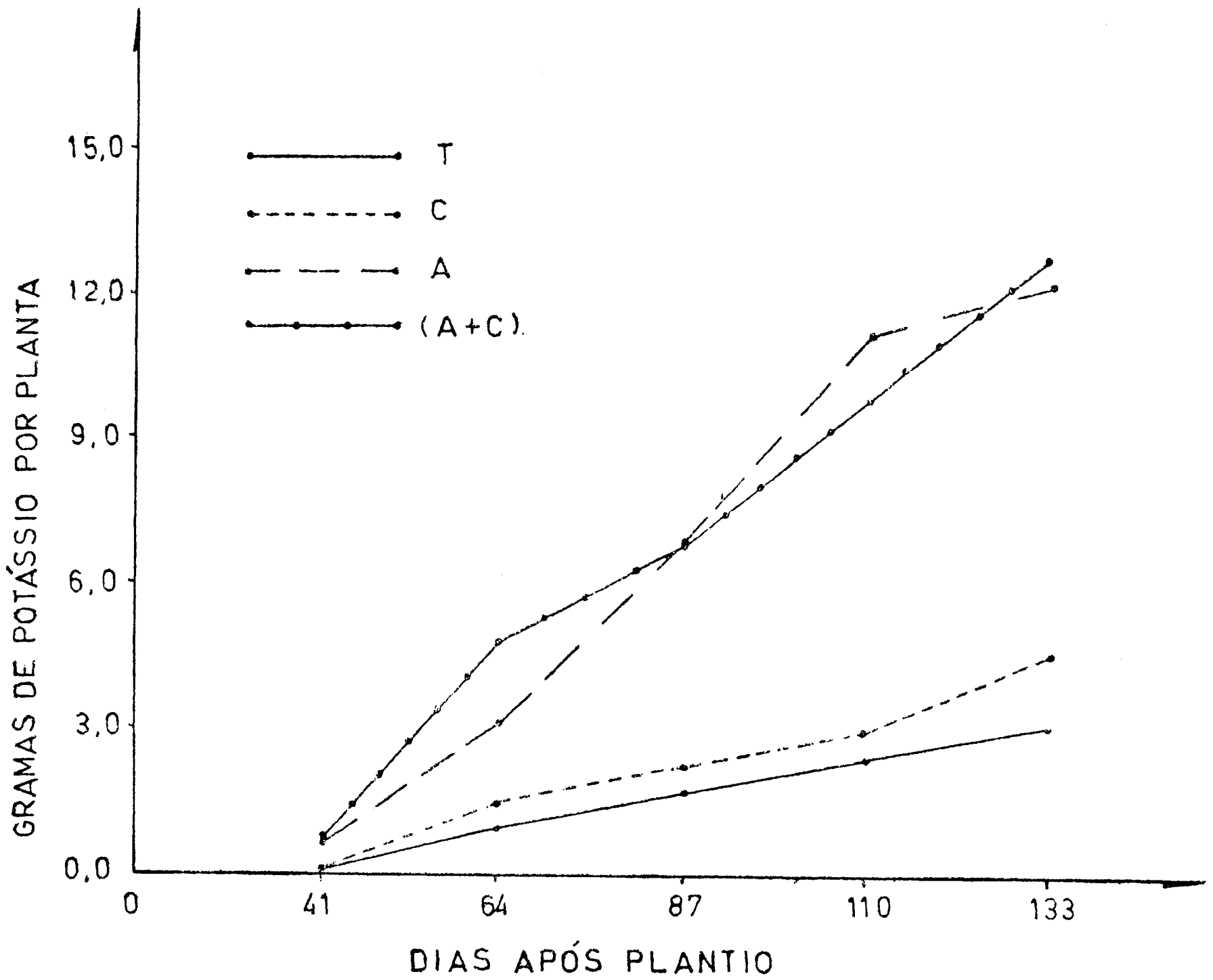

FIGURA 4 - Curvas mostrando marcha de absorção de potássio pelas plantas do cultivar "Campinas". Média de seis repetições.

QUADRO 6 - Extração média de potássio, em $\mathrm{kg} / \mathrm{ha}$, em vários estágios de desenvolvimento, pelo cultivar "Campinas".

\begin{tabular}{c|rrrrr}
\hline \multirow{2}{*}{$\begin{array}{c}\text { Trata- } \\
\text { mentos }\end{array}$} & \multicolumn{5}{|c}{ Dias após o plantio } \\
\cline { 2 - 6 } & 41 & 64 & 87 & 110 & 133 \\
\hline $\mathrm{T}$ & 1,22 & 14,46 & 22,05 & 31,27 & 42,56 \\
$\mathrm{C}$ & 1,67 & 20,45 & 32,07 & 41,22 & 62,34 \\
$\mathrm{~A}$ & 6,87 & 41,41 & 90,71 & 150,90 & 164,33 \\
$(\mathrm{~A}+\mathrm{C})$ & 7,29 & 64,90 & 91,47 & 131,85 & 171,61 \\
\hline
\end{tabular}




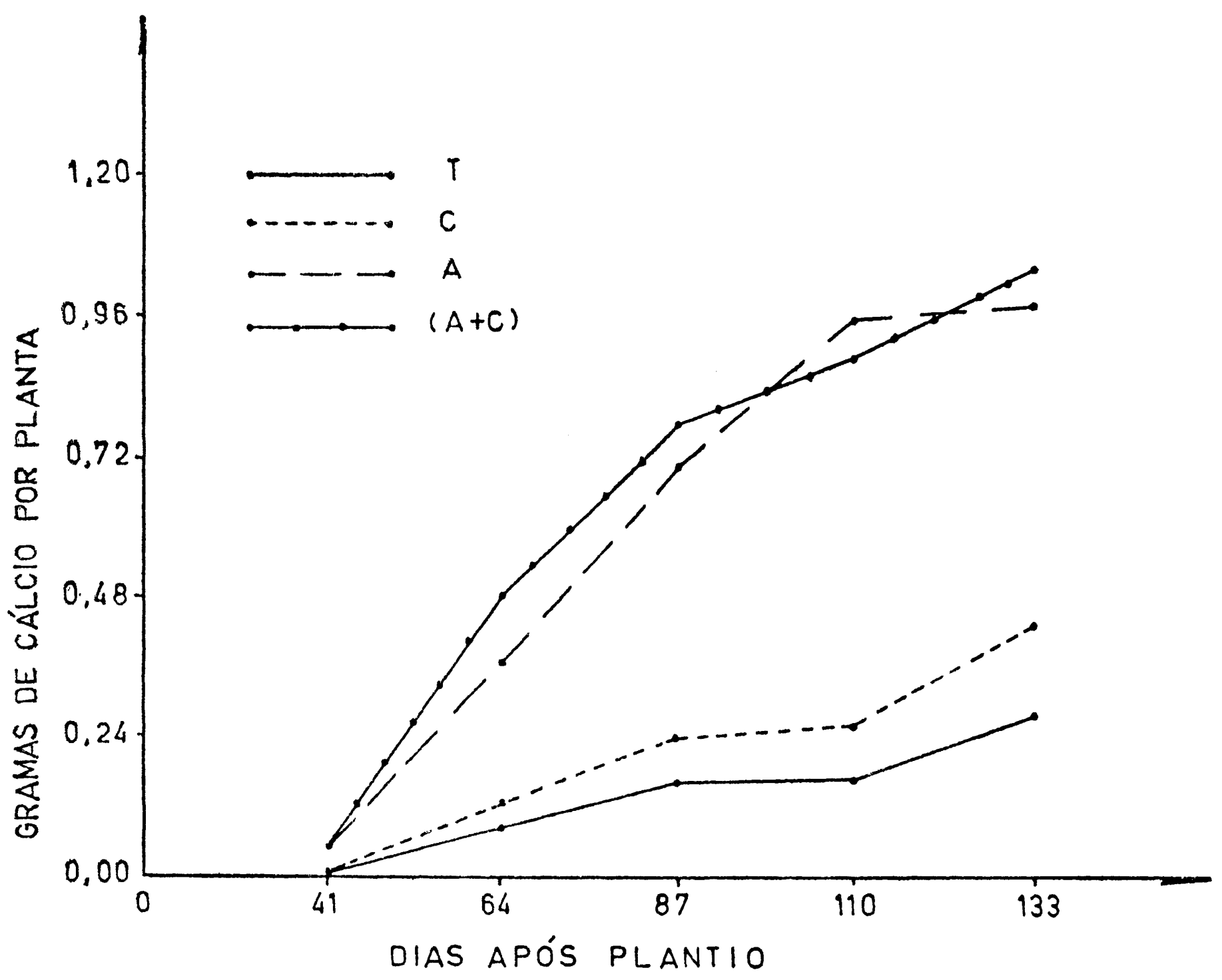

FIGURA 5 - Curvas mostrando marcha de absorção de cálcio pelas plantas do cultivar "Campinas". Média de seis repetições.

QUADRO 7 - Extração média de cálcio, em $\mathrm{kg} / \mathrm{ha}$, em vários estágios de desenvolvimento, pelo cultivar "Campinas".

\begin{tabular}{c|ccccc}
\hline \multirow{2}{*}{$\begin{array}{c}\text { Trata- } \\
\text { mentos }\end{array}$} & \multicolumn{5}{|c}{ Dias após o plantio } \\
\cline { 2 - 6 } & 41 & 64 & 87 & 110 & 133 \\
\hline $\mathrm{T}$ & 0,07 & 1,20 & 2,15 & 2,20 & 3,73 \\
$\mathrm{C}$ & 0,10 & 1,57 & 3,10 & 3,50 & 5,85 \\
$\mathrm{~A}$ & 0,44 & 4,89 & 9,49 & 12,67 & 13,07 \\
$(\mathrm{~A}+\mathrm{C})$ & 0,43 & 6,48 & 10,39 & 11,94 & 13,81 \\
\hline
\end{tabular}




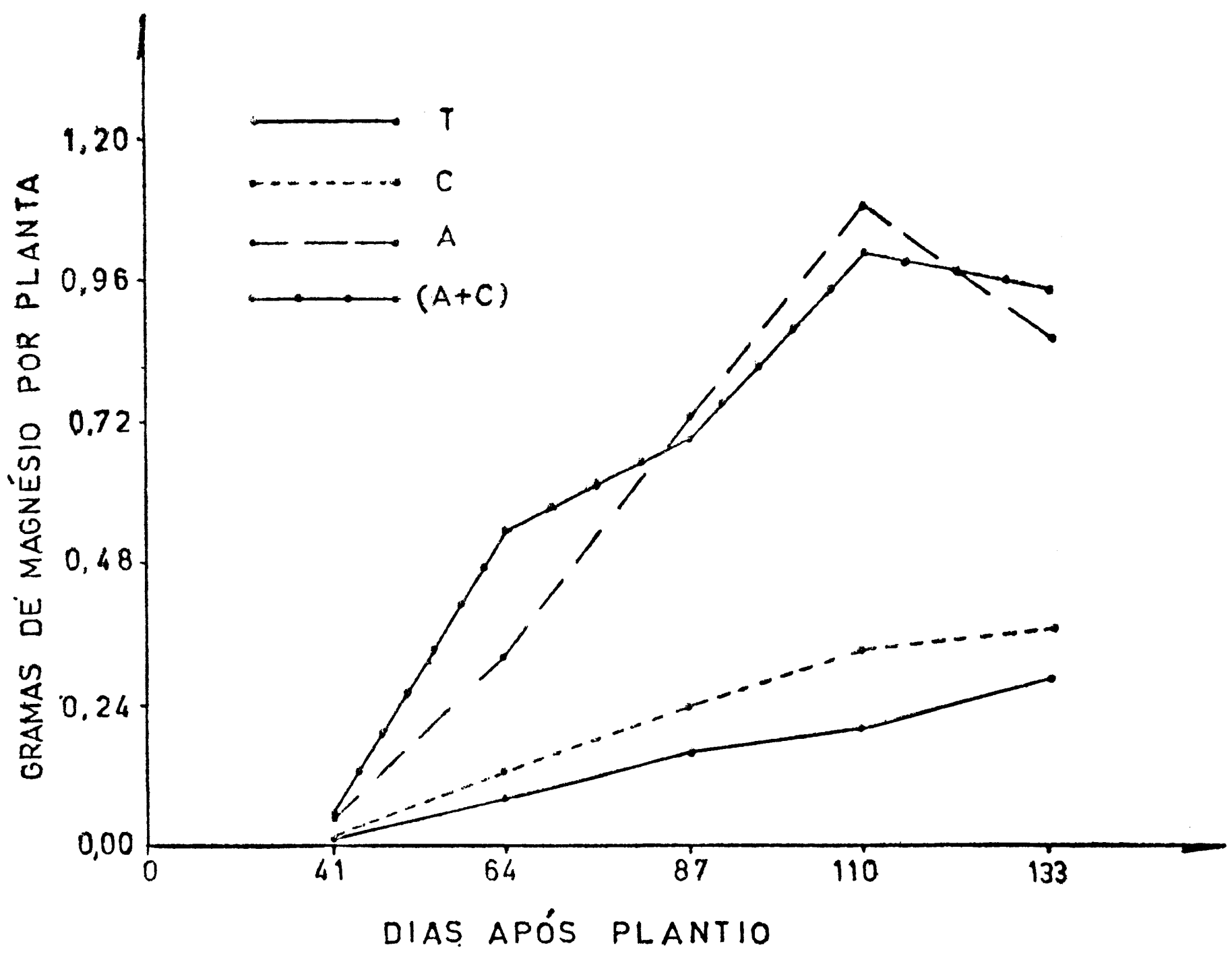

FIGURA 6 - Curvas mostrando marcha de absorção de magnésio pelas plantas do cultivar "Campinas". Média de seis repetições.

QUADRO 8 - Extração média de magnésio, em $\mathrm{kg} / \mathrm{ha}$, em vários estágios de desenvolvimento, pelo cultivar "Campinas".

\begin{tabular}{c|ccccc}
\hline \multirow{2}{*}{$\begin{array}{c}\text { Trata- } \\
\text { mentos }\end{array}$} & \multicolumn{5}{|c}{ Dias após o plantio } \\
\cline { 2 - 6 } & 41 & 64 & 87 & 110 & 133 \\
\hline $\mathrm{T}$ & 0,07 & 1,14 & 2,03 & 2,62 & 3,73 \\
$\mathrm{C}$ & 0,09 & 1,44 & 3,02 & 4,46 & 4,83 \\
$\mathrm{~A}$ & 0,40 & 4,18 & 9,23 & 14,87 & 11,83 \\
$(\mathrm{~A}+\mathrm{C})$ & 0,33 & 7,04 & 8,95 & 13,50 & 12,49 \\
\hline
\end{tabular}


QUADRO 9 - Pesos médios de frutos, sementes e cascas, em gramas por parcela, e porcentagens de sementes e cascas. Média de seis repetições.

\begin{tabular}{|c|c|c|c|c|c|c|}
\hline \multirow{2}{*}{$\begin{array}{l}\text { Trata- } \\
\text { mentos }\end{array}$} & \multirow{2}{*}{ Frutos } & \multirow{2}{*}{ Sementes } & \multirow{2}{*}{ Cascas } & \multicolumn{2}{|c|}{ Porcentagens } & \multirow{2}{*}{$\frac{\% \text { semen. }}{\% \text { casc. }}$} \\
\hline & & & & $\begin{array}{c}\text { Semen- } \\
\text { tes }\end{array}$ & Cascas & \\
\hline $\mathrm{T}$ & 918,19 & 639,91 & 278,28 & 69,69 & 30,34 & 2,30 \\
\hline $\mathrm{C}$ & $1.286,02$ & 895,72 & 390,30 & 69.65 & 30,35 & 2,29 \\
\hline A & $2.119,66$ & $1.515,45$ & 604,21 & 71,50 & 28,50 & 2,51 \\
\hline$(A+C)$ & $1.981,25$ & $1.486,91$ & 494,34 & 75,05 & 24,95 & 3,01 \\
\hline d.m.s. a $5 \%$ & 833,14 & 525,21 & 278,41 & 5,42 & 5,42 & \\
\hline C.V. $\%$ & 31,73 & 30,92 & 37,77 & 4,55 & 11,47 & \\
\hline
\end{tabular}

\section{SUMMARY}

TIME COURSE OF THE UPTAKE OF NITROGEN, PHOSPHORUS, POTASSIUM, CALCIUM AND MAGNESIUM IN CASTOR BEAN (Ricinus communis L.) CULTIVAR 'CAMPINAS'

This research work was carried out on the castor bean crop in order to evaluate the uptake of nitrogen, phosphorus, potassium, calcium and magnesium; and the effects of limestone and fertilizers and the combined effects of both, on uptake of macronutrients mentioned above, plant dry weight and yield. The experiment were conducted in a yellow dark latossol, sandy phase.

The maximum uptake period was not well caracterized, but for the treatments which received fertilizers, the greatest uptake for nitrogen, phosphorus, potassium and magnesium was between 41 and 110 days; for calcium, between 41 and 87 days, after sowing. Limestone had no effect on the plant dry weight and yield, but fertilizers increased the uptake of mineral nutrients, plant dry weight and yield.

\section{LITERATURA CITADA}

BRIGHAM, R. D., STAPP, B. R., WALKER, H. J. \& LYLES, W. E. 1963. Fertilizer rate test on three varieties of castorbeans grown on sprinkler-irrigated sandy soils, gaines county, Texas, 1962. Tex. agric. Exp. Stn, Prog. Rep. 2277.

CANECCHIO FILHO, V. \& FREIRE, E. S. 1958. Adubação da mamoneira, I. Experiências preliminares. Bragantia, 17:243-258.

CATANI, R. A., GALLO, J. R. \& GARGANTINI, H. 1955. Amostragem de solos, métodos de análise, interpretação e indicações gerais para fins de fertilidade. Inst. agron. Campinas. Bolm n. 69. 
COMISSÃO DE SOLOS. 1960. Levantamento de reconhecimento dos solos do Estado de São Paulo. Ministério da Agricultura, Serv. nac. de Pesq. Agron, Rio de J. Bolm n. 12.

GARGANTINI, H. \& GARCIA BLANCO, H. 1963. Marcha de absorção de nutrientes pelo tomateiro. Bragantia, 22(2):693-714.

GARGANTINI, H. \& GARCIA BLANCO, H. 1965. Absorção de nutrientes pela cultura do arroz. Bragantia, 24:515-528.

GLóRIA, N. A. DA, CATANI, R. A. \& MATUO, T. 1965a. O método do EDTA na determinação de cálcio e magnésio "trocável" do solo. Revta Agric., Piracicaba, 40:67-74.

GLÓRIA, N. A. DA, CATANI, R. A. \& MATUO, T. 1965b. Determinação de cálcio e magnésio em plantas pelo método EDTA. Anais Esc. sup. Agric. "Luiz de Queiroz", 21:219-228.

GRANATO, L. 1918. A mamoneira e o óleo de rícino. São Paulo, Tip. Levi.

HAAG, H. P. \& HOMA, P. 1968. Nutrição mineral de hortaliças IV. Absorção de nutrientes pela cultura da beringela. Anais Esc. sup. Agric. "Luiz de Queiroz", 25:177-188.

HOMA, P., HAAG, H. P. \& SARRUGE, J. R. 1969. Nutrição mineral de hortaliças. II. Absorção de nutrientes pela cultura de couve-flor. Solo, 61(1):9-16.

ITURRIETA ROJAS, A. 1970. Efeitos dos macronutrientes e do ferro no crescimento e composição química da mamoneira (Ricinus communis, L.) cultivada com soluções de nutrientes. Tese apresentada para obtenção do título de Magister Scientiae em Nutrição de Plantas. Piracicaba, 86 p.

LOOT, W. L., NERY, J. P., GALLO, J. R. \& MEDCALF, J. J. 1956. A técnica da análise foliar aplicada ao cafeeiro. Inst. agron. Campinas, Bolm n. 79.

MALAVOLTA, E. \& COURY, T. 1954. Apostila de práticas de Química Agrícola. Centro Acadêmico "Luiz de Queiroz". Piracicaba.

MALAVOLTA, E. 1965. Apuentes de classe n. ${ }^{\circ} 41$. Fisiogênicas Inst. Nac. de Tecnologia Agropecuária. Buenos Aires.

MARCOS FILHO, J. \& GODOY, O. P. 1971. Cultura da mamoneira. Depto. de Agricultura e Olericultura da Escola Superior de Agricultura "Luiz de Queiroz", $22 \mathrm{p}$.

NEPTUNE, A. M. L. 1964. Fertilidade do solo - Parte 1: Fundamentos de sua avaliação. Escola Superior de Agricultura "Luiz de Queiroz". Mimeo. 54 p.

ROCHA, J. L. V., CANECCHIO FILHO, V., FREIRE, E. S. \& SCARAMARI, H. 1964. Adubação da mamoneira. IV. Experiências de espaçamento x adubação (2." série). Bragantia, 23:257-269.

TUCKER, B. B. 1952. Castor beans: Their nutrient requirements, responses to fertilization treatments, and deficiency symptoms under controlled conditions. Thesis M. S., Oklahoma. 60 p.

ZINK, F. W. \& YAMAGUCHI, M. 1962. Studies on the growth and nutrient absorption of head lettuce. Hilgardia, 32:471-500.

ZINK, F. W. 1966. Studies on the growth rate and nutrient absorption of onion. Hilgardia. 37:203-218. 
